\title{
Cis and trans linkage of spin frustrated copper triangles creating $\mathrm{Cu}_{6}$ clusters
}

\author{
Basharat Ali a, b, Frédéric Gendron c, Xiao-Lei Li a, Boris Le Guennic *, c \\ and Jinkui Tang *,a, b
}

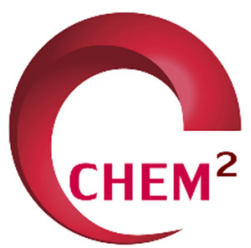

Emails: boris.leguennic@,univ-rennes1.fr, tang@,ciac.ac.cn

\begin{abstract}
a State Key Laboratory of Rare Earth Resource Utilization, Changchun Institute of Applied Chemistry, Chinese Academy of Sciences, Changchun 130022, P. R. China

b School of Applied Chemistry and Engineering, University of Science and Technology of China, Hefei 230026, P. R. China

c Univ Rennes, CNRS, ISCR (Institut des Sciences Chimiques de Rennes) - UMR 6226, F-35000 Rennes, France
\end{abstract}

\begin{abstract}
Two $C_{3}$-symmetric guanidine-based copper triangles bridged by acetates in a cis manner and by chloride anions in a trans manner, respectively gave rise to two antiferromagnetically coupled hexanuclear $\mathrm{Cu}^{\mathrm{II}}$ compounds, namely $\left[\mathrm{Cu}_{6} \mathrm{~L}_{2} \mathrm{Cl}(\mu-\mathrm{OAc})(\mathrm{DMF})_{3}\right] \cdot \mathrm{DMF}\left(\mathbf{C u}_{6}\right)$ and $\left[\mathrm{Cu}_{6} \mathrm{~L}_{2}(\mu-\mathrm{Cl})_{2}(\mathrm{DMF})_{4}\right] \quad\left(\mathbf{C u}_{6} \mathbf{C l}\right)$ (where L stands for fully deprotonated tris (2-hydroxybenzylidene) triaminoguanidinium chloride, $\mathrm{H}_{5} \mathrm{~L}$ ). The experimental magnetic data of the two compounds were analyzed theoretically. A relatively good agreement with the experimental data was obtained when using the wavefunction theory (CASSCF) in combination with DFT (B3LYP) calculations for the very strong antiferromagnetic coupling within the $\mathrm{Cu}_{3}$ triangles $\left(J_{\text {avg }}=-300 \mathrm{~cm}^{-1}\right.$ for $\mathbf{C u}_{6}$ and $J_{\text {avg }}=-250 \mathrm{~cm}^{-1}$ for $\mathbf{C} \mathbf{u}_{6} \mathbf{C l}$ ), leading to spin-frustrated systems. It is worth mentioning that the electronic structure of each $\mathrm{Cu}^{\mathrm{II}}$ center remains very similar in each complex with a Kramers ground state well separated from the first excited state (over $12000 \mathrm{~cm}^{-1}$ ) and weakly anisotropic $\left(g_{/ /} \approx 2.40\right.$ and $\left.g_{\perp} \approx 2.10\right)$.
\end{abstract}

Keywords: Spin frustration, Copper triangles, cis and trans, $\mathrm{Cu}_{6}$ cluster.

\section{Introduction}

Polynuclear $\mathrm{Cu}^{\mathrm{II}}$ compounds are continuously getting considerable attention in biology and magnetochemistry [1,2]. Symmetry plays a vital role to magnetochemistry; the overlapping of orbitals and consequently the exchange interactions among magnetic centers relies significantly on symmetry $[3,4]$. In this regard, strict threefold $C_{3}$ symmetric systems exhibit interesting properties applicable to phenomena such as single-molecule magnets [5] and spin frustration [6,7]. Recently, the latter has been used to make molecular electronic quantum bits based on triangular $\mathrm{Cu}^{\mathrm{II}}$ complexes [8,9]. Such triangular antiferromagnetically coupled molecular systems are particularly interesting because of their spin electric coupling effects. This phenomenon may be used to control molecular electronic quantum systems; actually, experimental evidence of such potential application has recently been reported [10-14].

The assembly of triangular units in larger aggregates has been accomplished by dimerization through $\mathrm{H}$ bonds [15,16], bridging counteranions [17,18], bi-topic amines [19], carboxylate/bis-carboxylato linkers [20,21] and carboxylate functionalized N,N ligands [22-27]. However, planar tri-topic ligands with strict $C_{3}$ symmetry are still rare and to the best of our knowledge mostly limited to triaminoguanidinium-based ligands [8, 28-30]. Interestingly, such type of ligands are capable of trapping three transition metal ions in a planar structure with three equivalent binding cavities, leading to somewhat short metal-metal contacts, through bridging by the N-N diazine unit of the central triaminoguanidinium moiety [31]. Indeed, it was found that the triaminoguanidinium bridging mode promotes antiferromagnetic exchange interactions among the metal centers through a $\sigma$ bond pathway including the N-N diazine group of the ligand $[1,8,28$ - 
32]. Large antiferromagnetic isotropic exchange and small antisymmetric exchange interactions are favorable for practical implementation. However, this combination is hardly present in most of the complexes reported so far [8, 28-30].

Recently, two antiferromagnetically coupled spin-frustrated trinuclear copper(II) triangles, i.e. $\left[\mathrm{Cu}_{3} \mathrm{~L}(\mathrm{bpy})_{3}\right] \mathrm{ClO}_{4} \cdot 3 \mathrm{DMF}\left(\mathbf{C u}_{3}\right.$ bpy) and $\left[\mathrm{Cu}_{3} \mathrm{~L}(\text { py })_{6}\right] \mathrm{ClO}_{4}\left(\mathbf{C u}_{3}\right.$ py) (bpy and py are bipyridine and pyridine, respectively), have been reported by Winfried Plass and co-workers [8,30]. Using the same metal-ligand combination, we have obtained two novel antiferromagnetic hexanuclear $\mathrm{Cu}^{\mathrm{II}}$ clusters, namely $\left[\mathrm{Cu}_{6} \mathrm{~L}_{2} \mathrm{Cl}(\mu\right.$ $\left.\mathrm{OAc})(\mathrm{DMF})_{3}\right] \cdot \mathrm{DMF}\left(\mathbf{C u}_{6}\right)$ and $\left[\mathrm{Cu}_{6} \mathrm{~L}_{2}(\mu-\mathrm{Cl})_{2}(\mathrm{DMF})_{4}\right]\left(\mathbf{C u}_{6} \mathbf{C l}\right)$ (Scheme 1). In both compounds, two trinuclear planar triangles with strict $C_{3}$ symmetry are bridged through acetate and chloride anions in $c$ is and trans manner, respectively, generating hexanuclear clusters. Interestingly, both complexes display strong antiferromagnetic exchange interactions among the copper centers through $\sigma$ bond pathway including the N-N diazine group of the ligand. Taking into account the structural similarity of $\mathbf{C u}_{6}$ and $\mathbf{C u}_{6} \mathbf{C l}$ with the reported complexes $\mathbf{C u}_{3}$ bpy and $\mathbf{C u}_{3}$ py, one may expect that these new compounds will behave as spin frustrated systems.

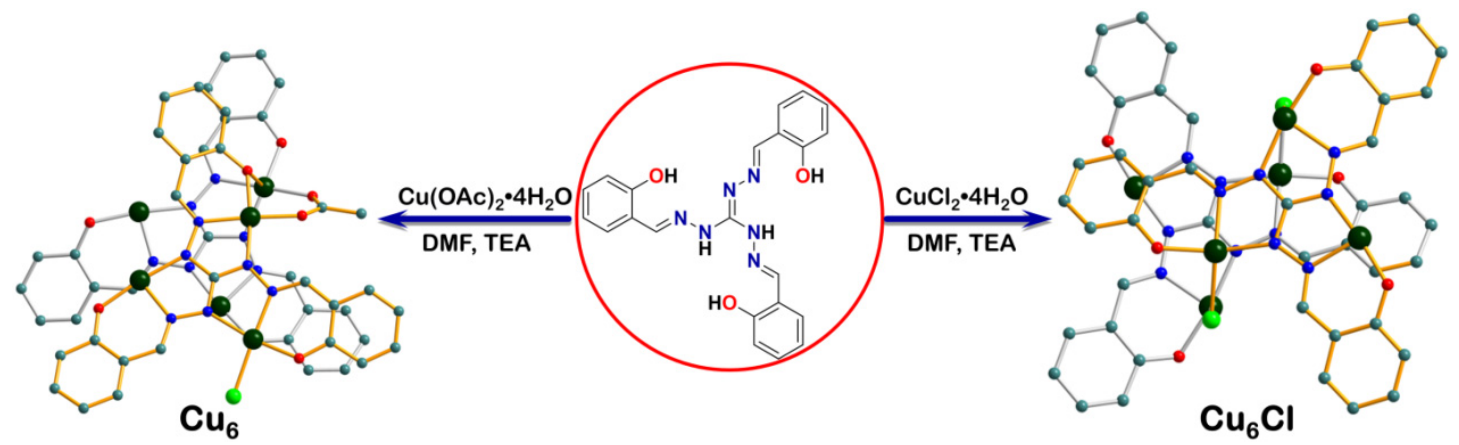

Scheme 1. Synthetic pathways to prepare the titled complexes (color codes: C, gray; Cu, dark green; O, red; $\mathrm{Cl}$, bright green; $\mathrm{N}$, blue). Hydrogen atoms, coordinated and lattice solvents are omitted for clarity.

The two bridged $\mathrm{Cu}_{3}$ triangles are shown with different bond colors.

\section{Results and Discussion}

Crystal Structures of Complexes $\mathbf{C u}_{6}$ and $\mathbf{C u}_{6} \mathbf{C l}$. The hexanuclear complex $\left[\mathrm{Cu}_{6} \mathrm{~L}_{2} \mathrm{Cl}(\mu\right.$ $\left.\mathrm{OAc})(\mathrm{DMF})_{3}\right] \cdot \mathrm{DMF}\left(\mathbf{C u}_{\mathbf{6}}\right)$, crystallizes in the triclinic space group $P \overline{\mathbf{1}}$. The unit cell contains one crystallographically independent hexanuclear neutral complex $\left[\mathrm{Cu}_{6} \mathrm{~L}_{2} \mathrm{Cl}(\mu-\mathrm{OAc})(\mathrm{DMF})_{3}\right]$ and one cocrystallized DMF molecule (Figure 1a). Crystallographic data, selected bond lengths and angles are given in Tables S1 and S2 (Supporting Information).

In $\mathbf{C u}_{6}$, two propeller-like planar $\mathrm{Cu}^{\mathrm{II}}$-triangles are bridged via $\mathrm{Cu} 1$ and $\mathrm{Cu} 4$ through an $\mathrm{O}, \mathrm{O}^{\prime}$-acetate anion in a cis manner (Cu1-O1, $1.953 \AA$ and Cu4-O5, $1.945 \AA$ ) to form a supramolecular hexanuclear cluster. A very weak bridging interaction through O7 $(2.378 \AA)$ of the deprotonated hydroxyl group of the ligand takes place between $\mathrm{Cu} 1$ and $\mathrm{Cu} 4$. Within each trinuclear unit, the deprotonated tri-topic ligand with a planar equilateral triangular arrangement coordinates three metallic centers (Figure 1a). Cu2 and Cu6 are four coordinated and display a square-planar geometry, while Cu1 is five coordinated with a squarepyramidal arrangement (Table S4, Figure S2). In all copper centers, three coordination sites are occupied by NNO donors from the tridentate pockets of the ligand. The fourth equatorial position is occupied by a DMF molecule in the case of $\mathrm{Cu} 2, \mathrm{Cu} 3$ and $\mathrm{Cu} 5$, a chloride for $\mathrm{Cu} 6$, and the oxygen atoms $\mathrm{O} 1$ and $\mathrm{O} 5$ of the bridging acetate for $\mathrm{Cu} 1$ and $\mathrm{Cu} 4$, respectively. All trans angles are within the range of $\sim 170-176^{\circ}$ for $\mathrm{Cu} 2$ and $\mathrm{Cu} 6$, which are trapped in an almost perfect square plane promoted by the planar rigid ligand. The axial fifth position of the only five coordinated $\mathrm{Cu} 1$ center is occupied by the oxygen atom $\mathrm{O} 7$ from the neighboring ligand. The distances between the copper centers connected through the rigid $\mathrm{N}-\mathrm{N}$ diazine channels of each ligand are in the range of 4.77-4.84 $\AA$ (Figure 1c). The bridging $\mathrm{Cu}-\mathrm{N}-\mathrm{N}-\mathrm{Cu}$ dihedral angles are ranging from 156.93 to $170.63^{\circ}$. Finally, the two planes formed by the two $\mathrm{Cu}_{3}$ triangles are nearly parallel to each other with a small dihedral angle of $7.825^{\circ}$ between them (Figure 1c).

$\mathbf{C u}_{6} \mathbf{C l}$ also crystallizes in the triclinic space group $P \overline{1}$. The asymmetric unit contains half of the molecule, vir. $\left[\mathrm{Cu}_{3} \mathrm{~L}(\mu-\mathrm{Cl})(\mathrm{DMF})_{2}\right]$, and the two triangular asymmetric units are bridged by $\mathrm{Cl}^{-}$ions (i.e. $\mathrm{Cl} 1$ and $\mathrm{Cl1}$ a), in a trans fashion. Hydrogen bonding between $\mathrm{H} 5$ and $\mathrm{Cl} 1$ (and between H5a and Cl1a) further stabilizes 
the hexanuclear cluster (Figure 1b and Figure S1). Crystallographic data, selected bond lengths and angles are given in Tables $\mathbf{S} 1$ and $\mathbf{S 3}$ (Supporting Information).
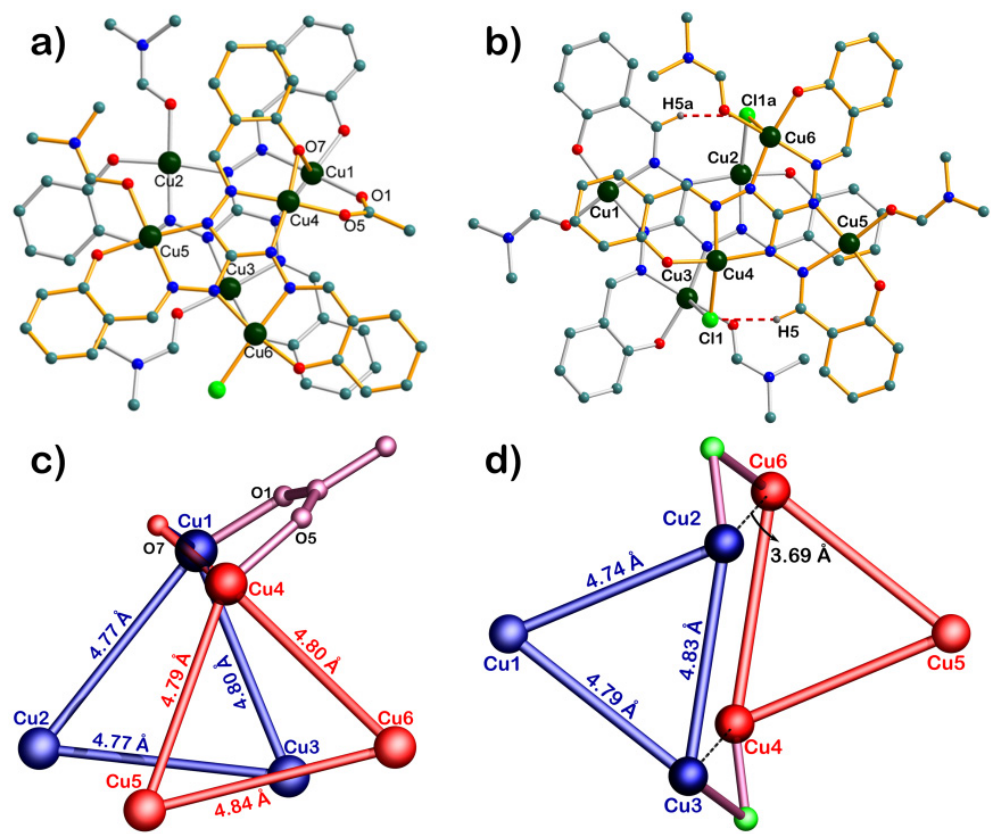

Figure 1. Molecular structures of a), $\mathbf{C u}_{6}$ and b), $\mathbf{C u}_{6} \mathbf{C l}$; hydrogen atoms and solvent molecules are omitted for clarity. Triangular units in $\mathbf{C u}_{6}$ (c) and $\mathbf{C u}_{6} \mathbf{C l}$ (d), shown with different bond colors and with the distances between the copper centers; the bridged trinuclear units are cis oriented in $\mathbf{C u}_{\mathbf{6}}$ and trans oriented in $\mathbf{C u}_{6} \mathbf{C l}$.

As observed for $\mathbf{C u}_{6}$, within each $\mathrm{Cu}_{3}$ unit (i.e. asymmetric unit) of $\mathbf{C u}_{6} \mathbf{C l}$, the planar and rigid tri-topic ligand generates an equilateral copper triangle (Figure $\mathbf{1 b}$ and Figure S5). $\mathrm{Cu} 1$ and $\mathrm{Cu} 3$ are four coordinated and display a square-planar geometry, while $\mathrm{Cu} 2$ is five coordinated with a square-pyramidal arrangement (Table S5, Figure S3). In all copper centers, three coordination sites are occupied by NNO donors of the tridentate pockets of the ligand. The fourth position is occupied by DMF molecules in the case of $\mathrm{Cu} 2$ and $\mathrm{Cu} 3$, and by a chloride anion for $\mathrm{Cu} 1$. The fifth, axial position of $\mathrm{Cu} 2$, which is the sole five coordinated center, is occupied by a bridging chloride anion. In $\mathrm{Cu} 1$ and $\mathrm{Cu} 3$, all trans angles are within the range of $\sim 155-173^{\circ}$ and the copper ions are trapped in almost perfect square planes generated by the rigid planar ligand. The distances between the copper centers connected through the trinucleating ligand are in the range of $4.74-4.83 \AA$ (Figure $2 \mathbf{d}$ ), similarly to $\mathbf{C u}_{6}$. The $\mathrm{Cu}-\mathrm{N}-\mathrm{N}-\mathrm{Cu}$ dihedral angles are ranging from 161.40 to $174.14^{\circ}$. In contrast to $\mathbf{C u}_{6}$, the $\mathrm{Cu}_{3}$ planes in $\mathbf{C} \mathbf{u}_{6} \mathbf{C l}$ are perfectly parallel to each other, the separation distance being of $3.37 \AA$ (Figure 2d).

The guanidine ligand $\mathrm{H}_{5} \mathrm{~L} \cdot \mathrm{HCl}$ has one double and two single bonds between the central carbon and nitrogen atoms. Upon coordination, the "C-N" bond lengths vary between 1.330(10) $\AA$ and 1.385(10) $\AA$ for $\mathbf{C u}_{6}$, and between 1.337(6) $\AA$ and 1.362(6) $\AA$ for $\mathbf{C u}_{6} \mathbf{C l}$. These bond lengths (that are intermediate between a double and single bond) show that the ligand double bond $(\mathrm{C}=\mathrm{N})$ is delocalized over four atoms (central " $\mathrm{CN}_{3}$ unit" of the ligand) in both complexes. The carbon and nitrogen atoms are sp ${ }^{2}$-hybridized; consequently, complexes with highly planar structures are formed.

All coordination bond lengths, trans angles and dihedral angles observed for $\mathbf{C u}_{6}$ and $\mathbf{C} \mathbf{u}_{6} \mathbf{C l}$ are well in line with those of the reported spin-frustrated triangles $\mathbf{C} \mathbf{u}_{3}$ bpy [8,28-30] and $\mathbf{C} \mathbf{C u}_{3}$ py [8,28-30]. Interestingly, the tiny change of metal salt leads to different bridging mode (cis or trans) of the $\mathrm{Cu}_{3}$ triangles in $\mathbf{C u}_{6}$ and $\mathbf{C u}_{6} \mathbf{C l}$. Given the spin-frustrated behaviors of $\mathbf{C u}_{3}$ bpy and $\mathbf{C u}_{3}$ py, similar interesting magnetic behaviors can be expected for $\mathbf{C u}_{6}$ and $\mathbf{C u}_{6} \mathbf{C l}$ (see below).

Magnetic studies. Temperature dependence molar susceptibility $\left(\chi_{\mathrm{M}} T\right)$ measurements for $\mathbf{C u}_{\mathbf{6}}$ and $\mathbf{C u}_{6} \mathbf{C l}$ were determined in the temperature range from 2 to $300 \mathrm{~K}$ (Figure 2). At room temperature, the $\chi_{\mathrm{M}} T$ 
values are 1.14 and $1.42 \mathrm{~cm}^{3} \mathrm{~K} \mathrm{~mol}^{-1}$ for $\mathbf{C u}_{\mathbf{6}}$ and $\mathbf{C u}_{\mathbf{6}} \mathbf{C l}$, respectively, which are significantly lower than the spin-only value expected for six independent $\mathrm{Cu}^{\mathrm{II}}$ ions $\left(\chi_{\mathrm{M}} T=2.6 \mathrm{~cm}^{3} \mathrm{~K} \mathrm{~mol}^{-1}\right.$ for $S=1 / 2$ and $g=$ 2.15). Upon lowering the temperature, the $\chi_{\mathrm{M}} T$ products further decline gradually and reach a plateau value of about $0.8 \mathrm{~cm}^{3} \mathrm{~K} \mathrm{~mol}^{-1}$ between 40 to $90 \mathrm{~K}$.

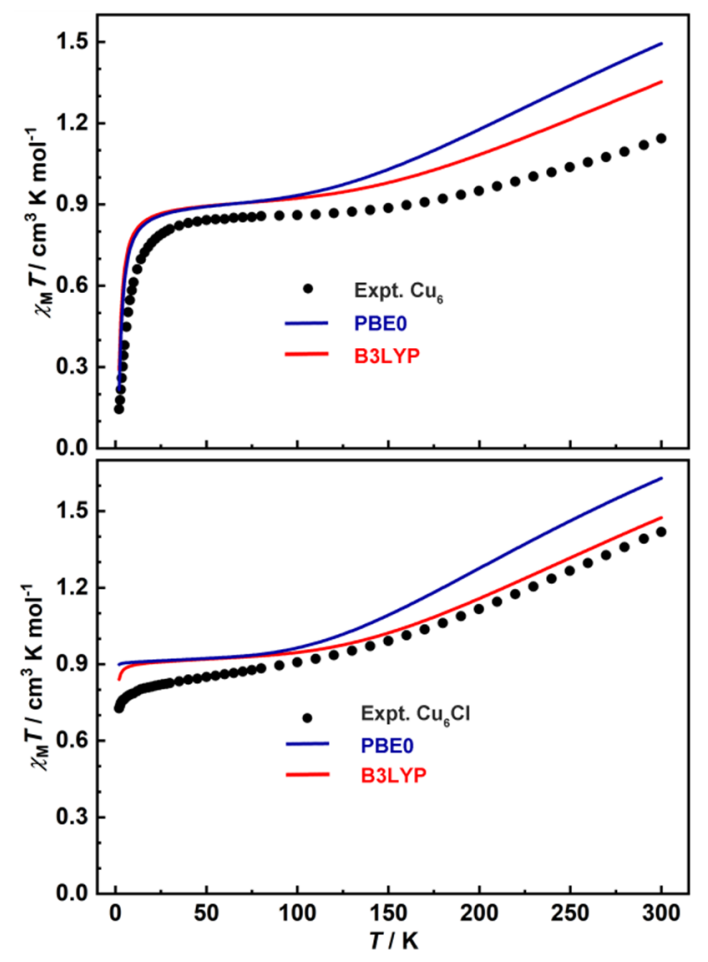

Figure 2. Calculated (plain lines) and experimental (filled circles) magnetic susceptibility $\left(\chi_{\mathrm{M}} T\right)$ as a function of the temperature for $\mathbf{C u}_{6}$ (top) and $\mathbf{C u}_{6} \mathbf{C l}$ (bottom). The results are shown for magnetic coupling constants calculated at the DFT level with the B3LYP and PBE0 hybrid functionals while the magnetic moments of each $\mathrm{Cu}^{\mathrm{II}}$ centers were obtained at the CASSCF level. The numerical values of these constants are given in Table 1.

This behavior indicates a strong anti-ferromagnetic exchange coupling with a ground spin state of $S=1 / 2$ within each triangle. Below $20 \mathrm{~K}$, the $\chi_{\mathrm{M}}$ T value drops down sharply, which suggests the existence of weak intermolecular interactions between the two $\mathrm{Cu}_{3}$ triangles in both complexes [27-29]. The field-dependence of the magnetization curves were also measured for $\mathbf{C u}_{6}$ and $\mathbf{C u}_{6} \mathbf{C l}$ under $2.0 \mathrm{~K}$ between $0-70 \mathrm{kOe}$ (Figure S4 and Figure S5). For complex $\mathbf{C u}_{6} \mathbf{C l}$, the magnetization increases more rapidly than for $\mathbf{C u}_{6}$, before $40 \mathrm{kOe}$ and then levelling off and reaching a plateau of $c a .2 \mu_{\mathrm{B}}$ at $70 \mathrm{kOe}$, which is consistent with a $S=1$ spin ground state for both complexes. However, a clear inflection at about $40 \mathrm{kOe}$ can be observed for $\mathbf{C u}_{\mathbf{6}}$ and after that, the magnetization increases more rapidly but without saturation, even under 70 $\mathrm{kOe}$, suggesting that the antiferromagnetic interactions are stronger than those observed for complex $\mathbf{C u}_{6} \mathbf{C l}$ and are overcome by applying a moderate field (Figure $\mathbf{S} 4$ and see calculations part).

Theoretical Calculations. The calculated magnetic susceptibilities for the two complexes are shown in Figure 2 and compared to the experimental data. A relatively good agreement is obtained with the experimental data when using the B3LYP functional for the calculation of the magnetic coupling constants (Figure 2, red lines). Interestingly, the different experimental behaviors of $\chi_{\mathrm{M}} T$ at low temperature are well reproduced by the calculations with a much smaller value of $\chi_{\mathrm{M}} T$ at $2 \mathrm{~K}$ in $\mathbf{C u}_{6}\left(\chi_{\mathrm{M}} T=0.29 \mathrm{~cm}^{3} \mathrm{~K} \mathrm{~mol}^{-1}\right.$ with B3LYP) than in $\mathbf{C u}_{6} \mathbf{C l}\left(\chi_{\mathrm{M}} T=0.84 \mathrm{~cm}^{3} \mathrm{~K} \mathrm{~mol}^{-1}\right)$. The differences between the two complexes when increasing the temperature can be rationalized looking at the calculated magnetic coupling constants given in Tables 1 and S7. Indeed, the presence of six $\mathrm{Cu}^{\mathrm{II}}$ centers with a pseudo-spin $S=1 / 2$ gives rise to 64 microstates that are energetically split by the 15 exchange coupling constants. As shown in Figure S7, the intermolecular interaction between the two triangles determines the evolution of the $\chi_{\mathrm{M}} T$ product at very 
low temperature. A small but sizable intermolecular antiferromagnetic coupling is calculated for $\mathbf{C u}_{\mathbf{6}}\left(J_{\mathrm{Cu}}\right.$ $\left.\mathrm{Cu} 4 \approx-20 \mathrm{~cm}^{-1}\right)$. This antiferromagnetic $J_{\text {inter }}$ leads to a non-magnetic ground state and a first triply degenerate excited state lying above at $c a .3 \mathrm{~cm}^{-1}$ (see Table S8 and Figure S8). Therefore, the $\chi_{\mathrm{M}} T$ product increases rapidly with the increase of the temperature as the excited state is populated, reaching a plateau at $c$. $20 \mathrm{~K}$. In $\mathbf{C u}_{\mathbf{6}} \mathbf{C l}$, the magnetic interaction between the two triangles is characterized by two small ferromagnetic interactions of $c a .6 \mathrm{~cm}^{-1}$. Surprisingly, these two ferromagnetic $J_{\text {inter }}$ strongly reduce the energy gap between the non-magnetic ground state and the first excited state $\left(\Delta E=0.16 \mathrm{~cm}^{-1}\right)$, leading to a larger value of $\chi_{\mathrm{M}} T$ at $2 \mathrm{~K}$ in $\mathbf{C u}_{6} \mathbf{C l}$. The increase of temperature over $20 \mathrm{~K}$ leads to a plateau of $\chi_{\mathrm{M}} T$ in both $\mathbf{C u}_{\mathbf{6}}$ and $\mathbf{C u}_{6} \mathbf{C l}$, with a slightly larger plateau in $\mathbf{C u}_{\mathbf{6}}$ than in $\mathbf{C u}_{\mathbf{6}} \mathbf{C l}$, due to overall larger $J_{\text {intra. }}$. It is worth mentioning that the electronic structure of each $\mathrm{Cu}^{\mathrm{II}}$ center (Figure S6 and Table S6) remains very similar in each complex with a Kramer's ground state well separated from the first excited state (over 12000 $\left.\mathrm{cm}^{-1}\right)$ and weakly anisotropic $\left(g_{/ \prime} \approx 2.40\right.$ and $\left.g_{\perp} \approx 2.10\right)$.

Table 1. Principal magnetic coupling constants $\left(J\right.$ in $\left.\mathrm{cm}^{-1}\right)$ for $\mathbf{C u}_{6}$ and $\mathbf{C u}_{6} \mathbf{C l}$ calculated at the DFT level with the B3LYP and PBE0 functionals. Additional data are given in Table S7. The atom labels correspond to those used in Figure 1.

\begin{tabular}{|c|c|c|c|c|c|}
\hline & & \multicolumn{2}{|c|}{$\mathrm{Cu}_{6}$} & \multicolumn{2}{|c|}{$\mathrm{Cu}_{6} \mathrm{Cl}$} \\
\hline & & B3LYP & PBE0 & B3LYP & PBE0 \\
\hline $\begin{array}{l}\mathrm{Cu} 1- \\
\mathrm{Cu} 2\end{array}$ & $J_{\text {intra }}$ & -372 & -305 & -180 & -157 \\
\hline $\begin{array}{l}\text { Cu1- } \\
\text { Cu3 }\end{array}$ & $\boldsymbol{J}_{\text {intra }}$ & -258 & -215 & -384 & -313 \\
\hline $\begin{array}{l}\mathrm{Cu} 1- \\
\mathrm{Cu} 4\end{array}$ & $\boldsymbol{J}_{\text {inter }}$ & -23 & -20 & -0 & 0 \\
\hline $\begin{array}{l}\mathrm{Cu} 2- \\
\mathrm{Cu} 3\end{array}$ & $J_{\text {intra }}$ & -277 & -235 & -186 & -157 \\
\hline $\begin{array}{l}\mathrm{Cu} 2- \\
\mathrm{Cu} 6\end{array}$ & $\boldsymbol{J}_{\text {inter }}$ & 0 & 0 & 6 & 5 \\
\hline $\begin{array}{l}\mathrm{Cu3}- \\
\mathrm{Cu} 4\end{array}$ & $J_{\text {inter }}$ & -0 & -0 & 6 & 5 \\
\hline $\begin{array}{l}\mathrm{Cu} 4- \\
\mathrm{Cu} 5\end{array}$ & $J_{\text {intra }}$ & -246 & -210 & -180 & -157 \\
\hline $\begin{array}{l}\mathrm{Cu} 4- \\
\mathrm{Cu} 6\end{array}$ & $J_{\text {intra }}$ & -283 & -235 & -186 & -157 \\
\hline $\begin{array}{l}\text { Cu5- } \\
\text { Cu6 }\end{array}$ & $J_{\text {intra }}$ & -366 & -299 & -384 & -313 \\
\hline
\end{tabular}

\section{Conclusions}

Using $C_{3}$-symmetric guanidine-based ligand, namely tris(2-hydroxybenzylidene)triaminoguanidinium chloride $\left(\mathrm{H}_{5} \mathrm{~L} \cdot \mathrm{HCl}\right)$, two novel hexanuclear $\mathrm{Cu}^{\mathrm{II}}$ compounds, vi . $_{[}\left[\mathrm{Cu}_{6} \mathrm{~L}_{2} \mathrm{Cl}(\mu-\mathrm{OAc})(\mathrm{DMF})_{3}\right] \cdot \mathrm{DMF}\left(\mathbf{C u}_{6}\right)$ and $\left[\mathrm{Cu}_{6} \mathrm{~L}_{2}(\mu-\right.$ $\left.\mathrm{Cl}_{2}(\mathrm{DMF})_{4}\right]\left(\mathbf{C u}_{6} \mathbf{C l}\right)$, were synthesized. Each ligand traps three metal ions in its NNO binding cavities, forming rigid planar triangular structures. In both complexes, different anions bridge the triangular units in cis or trans fashion, giving rise to the titled hexanuclear complexes. As for the reported compounds $\mathbf{C} \mathbf{u}_{3} \mathbf{b p y}$ and $\mathbf{C} \mathbf{u}_{3}$ py, $\mathbf{C u}_{6}$ and $\mathbf{C u}_{6} \mathbf{C l}$ exhibit strong antiferromagnetic interactions within the $\mathrm{Cu}_{3}$ triangles and spin frustration (as expected considering the properties of the related complexes described in the literature). Such magnetic properties in molecular systems is predicted to give rise to spin-electric coupling that allows manipulating their molecular spin states. Hence, this type of complexes may be seen as future potential candidates for molecular spintronics. Further studies are in progress to build larger cages from these triangular units using suitable new scaffolds. 
IV.

Additional Information

The Supporting Information is available free of charge at DOI 10.28954/2020.csq.10.001. Crystallographic data, selected bond lengths and angles, SHAPE analysis, crystal structure, magnetic measurements, and $a b$ initio details. CCDC $2021206\left(\mathbf{C u}_{\mathbf{6}}\right), 2021207\left(\mathbf{C u}_{\mathbf{6}} \mathbf{C l}\right)$ contain supplementary crystallographic data for this article. These data can be obtained free of charge from the Cambridge Crystallographic Data Centre via www.ccdc.cam.ac.uk/data request/cif.

\section{Materials and Methods}

General Information. All reagents of analytical grade were purchased from commercial sources and used without further purification. $\mathrm{H}_{5} \mathrm{~L} \cdot \mathrm{HCl}$ was synthesized with little modification as reported in the literature [33-35]. Triaminoguanidium chloride $(2.1 \mathrm{~g} ; 15 \mathrm{mmol})$, was dissolved in a hot mixture of ethanol and water ( $30 \mathrm{~mL}: 20 \mathrm{~mL}$ ) at $\mathrm{pH}=3$, adjusted by using $\mathrm{HCl}$. When the triaminoguanidium salt completely dissolved, a solution of salicylaldehyde $(0.5 \mathrm{mmol})$ in ethanol $(10 \mathrm{~mL})$ was added dropwise. A yellow precipitate of $\mathrm{H}_{5} \mathrm{~L} \cdot \mathrm{HCl}$ appeared immediately. The reaction mixture was further stirred overnight at room temperature and filtered to give almost quantitative yield ( 90\%) of the ligand [33-35]. Elemental analysis of C, H, and $\mathrm{N}$ was performed on a PerkinElmer 2400 analyzer. Powder X-ray diffraction analysis was performed on a Burker-D8 advance diffractometer by $\mathrm{Cu}-\mathrm{K} a(\lambda=1.5418 \AA)$ radiation at room temperature.

Synthesis of $\left[\mathrm{Cu}_{6} \mathrm{~L}_{2} \mathrm{Cl}(\mu-\mathrm{OAc})(\mathrm{DMF})_{3}\right] \cdot \mathrm{DMF}\left(\mathrm{Cu}_{6}\right)$ and $\left[\mathrm{Cu}_{6} \mathrm{~L}_{2}(\mu-\mathrm{Cl})_{2}(\mathrm{DMF})_{4}\right]\left(\mathrm{Cu}_{6} \mathrm{Cl}\right)$. Both complexes were synthesized using similar reaction conditions with different copper(II) salts. $\mathrm{Cu}(\mathrm{OAc})_{2} \cdot 6 \mathrm{H}_{2} \mathrm{O}(43.8 \mathrm{mg}, 0.15 \mathrm{mmol})$ or $\mathrm{CuCl}_{2} \cdot 6 \mathrm{H}_{2} \mathrm{O}(36.3 \mathrm{mg}, 0.15 \mathrm{mmol})$ and $\mathrm{H}_{5} \mathrm{~L} \cdot \mathrm{HCl}(22.6 \mathrm{mg}, 0.05$ $\mathrm{mmol})$ were dissolved in methanol $(20 \mathrm{~mL})$ followed by the addition of triethylamine $(0.035 \mathrm{~mL}, 0.25$ mmol) with continuous stirring. After 10 minutes, precipitation was observed in both cases; the reaction mixtures were further stirred for an hour, filtered and the solids were dried in air. Finally, the dried solids were dissolved in DMF $(3 \mathrm{~mL})$ and the solutions were left unperturbed in air. After a week, dark green cube-like crystals (quantitative yields), suitable for single crystal measurements, were obtained for $\mathbf{C u}_{6}$ and $\mathbf{C u}_{6} \mathbf{C l}$. Elemental Anal. Calcd. for $\mathrm{C}_{58} \mathrm{H}_{61} \mathrm{ClCu}_{6} \mathrm{~N}_{16} \mathrm{O}_{12}\left(\mathbf{C u}_{6}\right)$ : C, 43.79; H, 3.86; N, 14.09. Found: C, 43.77; $\mathrm{H}, 3.85 ; \mathrm{N}, 14.06$. and $\mathrm{C}_{56} \mathrm{H}_{58} \mathrm{Cl}_{2} \mathrm{Cu}_{6} \mathrm{~N}_{16} \mathrm{O}_{10}\left(\mathbf{C u}_{6} \mathbf{C l}\right)$ : C, 42.91; H, 3.73; N, 14.30. Found: C, 42.92; H, 3.72; N, 14.28 .

Crystallography. Crystal data, structural refinement and collection of data for complexes $\mathbf{C u}_{\mathbf{6}}$ and $\mathbf{C u}_{\mathbf{6}} \mathbf{C l}$ are given in Table S1. Bond lengths and angles are summarized in Tables S2 and S3, respectively. Single crystals of the titled complexes were mounted on glass fibers under a microscope, and diffraction data were collected at the corresponding temperatures (see Table S1) using a Bruker AXS D8 Venture singlecrystal diffractometer equipped with graphite-monochromatized Mo $\mathrm{K} a(\lambda=0.71073 \AA)$. The molecular drawings and mean plane analyses were made with DIAMOND (version 3.1). The structures were solved by direct methods, SHELXT and refined by full-matrix least-squares methods based on $F^{2}$ (SHELXL) in the Olex2 package $[36,37]$.

Magnetic susceptibility measurements. Magnetic susceptibility measurements were carried out on polycrystalline sample with a Quantum Design MPMS-XL7 SQUID magnetometer equipped with a $7 \mathrm{~T}$ magnet, in the temperature range from 2 to $300 \mathrm{~K}$. Diamagnetic corrections of the constituent atoms were determined from Pascal's constants [38].

$\boldsymbol{A} \boldsymbol{b}$ initio calculations. The electronic structure and the magnetic properties of each Cu center were first calculated with wavefunction theory (WFT) using the complete-active space (CAS) self-consistent field (SCF) approach [39] as implemented in the OpenMolcas software package [40]. Here, five of the paramagnetic $\mathrm{Cu}^{\mathrm{II}}$ atoms in the $\mathrm{X}$-ray structures were replaced by diamagnetic $\mathrm{Z} \mathrm{n}^{\mathrm{II}}$ centers. The calculations were first carried out at the scalar (SR) level using the second-order Douglas-Kroll-Hess scalar relativistic Hamiltonian [41-43], in combination with the all electron atomic natural orbital relativistically contracted basis set (ANO-RCC) [44,45]. The basis sets were contracted to the triple- $\zeta$ plus polarization (TZP) quality for the $\mathrm{Cu}(21 \mathrm{~s} 15 \mathrm{p} 10 \mathrm{~d} 6 \mathrm{f} 4 \mathrm{~g} 2 \mathrm{~h} / 6 \mathrm{~s} 5 \mathrm{p} 3 \mathrm{~d} 2 \mathrm{f} 1 \mathrm{~g})$ and $\mathrm{Cl}(17 \mathrm{~s} 12 \mathrm{p} 5 \mathrm{~d} 4 \mathrm{f} 2 \mathrm{~g} / 5 \mathrm{~s} 4 \mathrm{p} 2 \mathrm{~d} 1 \mathrm{f})$ atoms, as well as for the $\mathrm{N}$ and $\mathrm{O}$ atoms coordinated to the paramagnetic center $(\mathrm{N}, \mathrm{O}=14 \mathrm{~s} 9 \mathrm{p} 5 \mathrm{~d} 3 \mathrm{f} 2 \mathrm{~g} / 4 \mathrm{~s} 3 \mathrm{p} 2 \mathrm{~d} 1 \mathrm{f})$. The 
$\mathrm{Zn}$ atoms were treated with a double- $\zeta$ plus polarization (DZP) basis set $(21 \mathrm{~s} 15 \mathrm{p} 10 \mathrm{~d} 6 \mathrm{f} 4 \mathrm{~g} 2 \mathrm{~h} / 5 \mathrm{~s} 4 \mathrm{p} 2 \mathrm{~d} 1 \mathrm{f})$, whereas the rest of the $\mathrm{C}, \mathrm{N}, \mathrm{O}$ and $\mathrm{H}$ atoms were treated with a double- $\zeta$ basis set $(\mathrm{C}, \mathrm{N}, \mathrm{O}=$ $14 \mathrm{~s} 9 \mathrm{p} 5 \mathrm{~d} 3 \mathrm{f} 2 \mathrm{~g} / 3 \mathrm{~s} 2 \mathrm{p} ; \mathrm{H}=8 \mathrm{~s} 4 \mathrm{p} 3 \mathrm{~d} 1 \mathrm{f} / 2 \mathrm{~s})$. State-average calculations were performed by considering the five lowest spin-doublet states and an active space formed by 11 electrons spanning 11 orbitals as depicted in Figure S6. These 11 orbitals correspond to the five $3 d$ orbitals of the $\mathrm{Cu}^{\mathrm{II}}$ ion, plus five $3 d$ orbitals to take into account the double-shell effect, and one ligand-centered orbital that can form a bonding $\sigma$ interaction with the metal-centered orbitals. The spin-orbit coupling (SOC) was then introduced by a state interaction within the basis of spin-orbit free states using the restricted active space state interaction (RASSI) approach [46]. The EPR g-factors were calculated according to Reference [47] as implemented in the RASSI module of OpenMolcas, whereas the magnetic susceptibility and magnetization calculations were performed using the Single-Aniso and Poly-Aniso modules of OpenMolcas as detailed in Reference [48].

In order to evaluate the magnetic coupling between the $\mathrm{Cu}^{\mathrm{II}}$ centers, Kohn-Sham density functional theory (DFT) were carried out using the Amsterdam Density Functional (ADF) software package [49-51]. The magnetic coupling constants calculations where performed on the X-ray structure where four of the paramagnetic $\mathrm{Cu}^{\mathrm{II}}$ atoms were replaced by diamagnetic $\mathrm{Zn}^{\mathrm{II}}$ centers. Such substitution leads to a model system with two $\mathrm{Cu}^{\mathrm{II}}$ centers of spin $1 / 2$, giving rise either to a triplet or a singlet spin state.

These calculations utilized the scalar all-electron zeroth-order regular approximation (ZORA) [52] along with the spin-unrestricted formalism. The open-shell singlet state was calculated using the broken symmetry (BS) approach developed by L. Noodleman [53]. The hybrid functionals PBE0 [54,55] (PerdewBurke-Ernzerhof) with $25 \%$ of exact Hartree-Fock exchange (eX) and B3LYP [56] (Becke, threeparameter Lee-Yang-Parr) with $20 \% \mathrm{eX}$, were employed along with the triple- $\zeta$ polarized Slater-type orbital (STO) all-electron basis set, with one set of polarization function for all atoms (TZP) [57].

The magnetic interaction was then assessed with the computation of the magnetic coupling constant $J_{a b}$, which corresponds to the energy difference between the triplet and singlet states based on the following Heisenberg-Dirac-van Vleck Hamiltonian [58-60]:

$$
\hat{H}=-\sum_{a>b} J_{a b} \cdot \hat{S}_{a} \cdot \hat{S}_{b}
$$

and with the help of the following spin-projected formula:

$$
J_{a b}=2\left[E_{B S}-E_{T}\right] /\left[\left\langle S^{2}\right\rangle_{T}-\left\langle S^{2}\right\rangle_{B S}\right]
$$

where $\left\langle S^{2}\right\rangle_{B S}$ and $\left\langle S^{2}\right\rangle_{T}$ correspond to the calculated square of the spin operator for both spin states, and equal to $c a .1$ and 2 for systems containing two unpaired electrons.

The magnetic susceptibility of the $\mathbf{C u}_{6}$ and $\mathbf{C u}_{6} \mathbf{C l}$ complexes were then calculated using the PolyAniso module as implemented in the OpenMolcas package, with the following spin Hamiltonian:

$$
\widehat{H}=\mu_{B} \sum_{i} g_{i} \cdot \hat{S}_{i} \cdot B-\sum_{a, b} J_{a b} \cdot \hat{S}_{a} \cdot \hat{S}_{b}
$$

where the magnetic moments of each $\mathrm{Cu}^{\mathrm{II}}$ centers were obtained from the WFT calculations and the magnetic coupling constants from DFT calculations. It is worth mentioning that such a computational strategy has been successfully applied on a related trinuclear copper(II) complex [9].

\section{Conflict of Interests}

The authors declare no competing financial interests.

\section{Acknowledgements}

We thank the National Natural Science Foundation of China (Grants 21525103, 21871247 and 21801237) and Key Research Program of Frontier Sciences, CAS (Grant ZDBS-LY-SLH023) for financial support. J. T. gratefully acknowledges support of the Royal Society-Newton Advanced Fellowship (NA160075). 
B.A is grateful for the support through CAS-TWAS President's Fellowship. F. G. and B. L. G. thanks the French GENCI/IDRIS-CINES centers for high-performance computing resources and acknowledge the Stratégie d'Attactivité Durable (SAD18006 - LnCPLSMM) for financial support.

\section{References}

[1] Plaul, D.; Bohme, M.; Ostrovsky, S.; Tomkowicz, Z.; Gorls, H.; Haase, W.; Plass, W., Inorg. Chem., 2018, 57, 106-119.

[2] Christou, G.; Gatteschi, D.; Hendrickson, D. N.; Sessoli, R., Mrs. Bull., 2000, 25, 66-71.

[3] Weihe, H.; Gudel, H. U., Inorg. Chem., 1997, 36, 3632-3639.

[4] Böhme, M.; Schuch, D.; Buchholz, A.; Görls, H.; Plass, W., Anorg. Allg. Chem., 2020, 646, 166-174.

[5] Glaser, T.; Heidemeier, M.; Weyhermüller, T.; Hoffmann, R.-D.; Rupp, H.; Müller, P., Angew. Chem. Int. Ed., 2006, 45, 6033-6037.

[6] Schnack, J., Dalton Trans. 2010, 39, 4677-4686.

[7] Baker, M. L.; Timco, G. A.; Piligkos, S.; Mathieson, J. S.; Mutka, H.; Tuna, F.; Kozlowski, P.; Antkowiak, M.; Guidi, T.; Gupta, T.; Rath, H.; Woolfson, R. J.; Kamieniarz, G.; Pritchard, R. G.; Weihe, H.; Cronin, L.; Rajaraman, G.; Collison, D.; McInnes, E. J. L.; Winpenny, R. E. P., Proc. Natl. Acad. Sci. U. S. A., 2012, 109, 19113-19118.

[8] Spielberg, E. T.; Gilb, A.; Plaul, D.; Geibig, D.; Hornig, D.; Schuch, D.; Buchholz, A.; Ardavan, A.; Plass, W.; Inorg. Chem., 2015, 54, 3432-3438.

[9] Kintzel, B.; Böhme, M.; Liu, J.; Burkhardt, A.; Mrozek, J.; Buchholz, A.; Ardavan, A.; Plass, W.; Chem. Commun., 2018, 54, 12934-12937.

[10] Liu, A.; Almeida, D. B.; Bae, W. K.; Padilha, L. A.; Cundiff, S. T., Phys. Rev. Lett., 2019, 123, 057403.

[11] Boudalis, A. K.; Robert, J.; Turek, P., Chem. Eur. J., 2018, 24, 14896-14900.

[12] Gutfleisch, O.; Willard, M. A. E.; Chen, C. H.; Sankar, S. G.; Liu, J. P., Adv. Mater., 2011, 23, 821-842.

[13] Fittipaldi, M.; Cini, A.; Annino, G.; Vindigni, A.; Caneschi, A.; Sessoli, R., Nat. Mater., 2019, 18, 329334.

[14] Le Guennic, B.; Petit, S.; Chastanet, G.; Pilet, G.; Amor, N. B., Robert, V., Inorg. Chem., 2008, 47, 572577.

[15] Mathivathanan, L.; Rivera-Carrillo, M.; Raptis, R. G., Inorg. Chim. Acta., 2012, 391, 201-205.

[16] Su, C.-Y.; Tong, Y.-Z.; Yuan, F.-C.; Wang, Q.-L.; Ma, Y.; Yang, G.-M.; Liao, D.-Z., Inorg. Chim. Acta., 2014, 423, 545-549. 
[17] Zheng, L.-L.; Leng, J.-D.; Zheng, S.-L.; Zhaxi, Y.-C.; Zhang, W.-X.; Tong, M.-L., CrystEngComm., 2008, 10, 1467-1473.

[18] Di Nicola, C.; Garau, F.; Gazzano, M.; Monari, M.; Pandolfo, L.; Pettinari, C.; Pettinari, R., Cryst. Growth Des., 2010, 10, 3120-3131.

[19] Di Nicola, C.; Garau, F.; Gazzano, M.; da Silva, M.; Lanza, A.; Monari, M.; Nestola, F.; Pandolfo, L.; Pettinari, C.; Pombeiro, A. J. L., Cryst. Growth Des., 2012, 12, 2890-2901.

[20] Massignani, S.; Scatena, R.; Lanza, A.; Monari, M.; Condello, F.; Nestola, F.; Pettinari, C.; Zorzi, F.; Pandolfo, L., Inorg. Chim. Acta., 2017, 455, 618-626.

[21] Contaldi, S.; Di Nicola, C.; Garau, F.; Karabach, Y. Y.; Martins, L. M. D. R. S.; Monari, M.; Pandolfo, L.; Pettinari, C.; Pombeiro, A. J. L., Dalton Trans., 2009, 4928-4941.

[22] Vasylevs'kyy, S. I.; Senchyk, G. A.; Lysenko, A. B.; Rusanov, E. B.; Chernega, A. N.; Jezierska, J.; Krautscheid, H.; Domasevitch, K. V.; Ozarowski, A., Inorg. Chem., 2014, 53, 3642-3654.

[23] Chen, D.-M.; Zhang, X.-P.; Shi, W.; Cheng, P., Inorg. Chem., 2015, 54, 5512-5518.

[24] Adarsh, N. N.; Dirtu, M. M.; Naik, A. D.; Leonard, A. F.; Campagnol, N.; Robeyns, K.; Snauwaert, J.; Fransaer, J.; Su, B. L.; Garcia, Y., Chem. Eur. J., 2015, 21, 4300-4307.

[25] Laessig, D.; Lincke, J.; Moellmer, J.; Reichenbach, C.; Moeller, A.; Glaeser, R.; Kalies, G.; Cychosz, K. A.; Thommes, M.; Staudt, R.; Krautscheid, H., Angew. Chem. Int. Ed., 2011, 50, 10344-10348.

[26] Lincke, J.; Laessig, D.; Kobalz, M.; Bergmann, J.; Handke, M.; Moellmer, J.; Lange, M.; Roth, C.; Moeller, A.; Staudt, R.; Krautscheid, H., Inorg. Chem., 2012, 51, 7579-7586.

[27] Lincke, J.; Laessig, D.; Stein, K.; Moellmer, J.; Kuttatheyil, A. V.; Reichenbach, C.; Moeller, A.; Staudt, R.; Kalies, G.; Bertmer, M.; Krautscheid, H., Dalton Trans., 2012, 41, 817-824.

[28] Anwar, M. U.; Thompson, L. K.; Dawe, L. N., Dalton Trans., 2011, 40, 1437-1440.

[29] Escuer, A.; Vlahopoulou, G.; Lloret, F.; Mautner, F. A., Eur. J. Inorg. Chem., 2014, 83-92.

[30] Kintzel, B.; Bohme, M.; Liu, J. J.; Burkhardt, A.; Mrozek, J.; Buchholz, A.; Ardavan, A.; Plass, W., Chem. Commun., 2018, 54, 12934-12937.

[31] Plass, W., Coord. Chem. Rev., 2009, 253, 2286-2295.

[32] Matsumoto, T.; Sato, Y.; Shiga, T.; Oshio, H., Inorg. Chem. Front., 2015, 2, 725-730.

[33] Muller, I. M.; Robson, R., Angew. Chem. Int. Ed., 2000, 39, 4357-4359.

[34] Ion, A. E.; Spielberg, E. T.; Görls, H.; Plass, W., Inorg. Chim. Acta., 2007, 360, 3925-3931.

[35] Winkelmann, E.; Raether, W., DE-B 2104346, 1972. Chem. Abstr., 1972, 126264. 
[36] Sheldrick, G. M., Acta Cryst. A., 2015, 71, 3-8.

[37] Sheldrick, G. M., Acta Cryst. C., 2015, 71, 3-8.

[38] Bain, G. A.; Berry, J. F., J. Chem. Educ., 2008, 85, 532-536.

[39] Roos, B. O.; Taylor, P. R.; Sigbahn P. E. M., Chem. Phys., 1980, 48, 157-173.

[40] Fdez. Galván, I.; Vacher, M.; Alavi, A.; Angeli, C.; Aquilante, F.; Autschbach, J.; Bao, J. J.; Bokarev, S. I.; Bogdanov, N. A.; Carlson, R. K.; Chibotaru, L. F.; Creutzberg, J.; Dattani, N., Delcey, M. G.; Dong, S. S.; Dreuw, A.; Freitag, L., Frutos, L. M.; Gagliardi, L.; Gendron, F.; Giussani, A.; González, L.; Grell, G.; Guo, M.; Hoyer, C. E.; Johansson, M.; Keller, S.; Knecht, S.; Kovačević, G.; Källman, E.;Manni, ～G. L.; Lundberg, M.; Ma, Y.; Mai, S.; Malhado, J. P.; Malmqvist, P. Å.; Marquetand, P.; Mewes, S. A.; Norell, J.; Olivucci, M.; Oppel, M.; Phung, Q. M.; Pierloot, K.; Plasser, F.; Reiher, M.; Sand, A. M.; Schapiro, I.; Sharma, P.; Stein, C. J.; Sørensen, L. K.; Truhlar, D. G.; Ugandi, M.; Ungur, L.; Valentini, A.; Vancoillie, S.; Veryazov, V.; Weser, O.; Wesołowski, T. A.; Widmark, P.-O.; Wouters, S.; Zech, A.; Zobel, J. P; Lindh, R., J. Chem. Theory Comput., 2019, 15, 5925-5964.

[41] Douglas, M.; Kroll, N. M., Ann. Phys., 1974, 82, 89-155.

[42] Hess, B. A., Phys. Rev. A., 1985, 32, 756-763.

[43] Hess, B. A., Phys. Rev. A., 1986, 33, 3742-3748.

[44] Widmark, P.-O.; Malmqvist, P.-Å.; Roos, B. O., Theor. Chim. Acta., 1990, 77, 291-306.

[45] Roos, B. O.; Lindh, R.; Malmqvist, P.-Å.; Veryazov, V; Widmark, P.-O., J. Phys. Chem. A., 2004, 108, 2851-2858.

[46] Malmqvist, P. Å.; Roos, B. O.; Schimmelpfennig, B., Chem. Phys. Lett., 2002, 357, 230-240.

[47] Bolvin, H.; ChemPhysChem, 2006, 7, 1575-1589.

[48] Chibotaru, L. F.; Ungur, L., J. Chem. Phys., 2012, 137, 064112.

[49] Fonseca Guerra, C., Snijders, J. G.; te Velde G.; Baerends, E. J., Theor. Chem. Acc., 1998, 99, 391-403.

[50] te Velde, G.; Bickelhaupt, F. M.; Baerends, E. J.; Fonseca Guerra, C.; van Gisbergen, S. J. A.; Snijders, J. G.; Ziegler ,T., J. Comput. Chem., 2001, 22, 931-967.

[51] Baerends; E. J. Z. T.; Atkins, A. J.; Autschbach, J.; Bashford, D.; Baseggio, O.; Bérces, A. B. F. M.; Bo, C.; Boerritger, P. M.; Cavallo, L.; Daul, C.; Chong, D. P. C. D. V.; Deng, L.; Dickson, R. M.; Dieterich, J. M.; Ellis, D. E.; van Faassen, M. G. A.; Giammona, A.; van Gisbergen, S. J. A.; Goez, A.; Götz, A. W.; Gusarov, S. H. F. E.; van den Hoek, P.; Hu, Z.; Jacob, C. R.; Jacobsen, H.; Jensen, L.; Joubert, L. K. J. W.; van Kessel, G.; König, C.; Kootstra, F.; Kovalenko, A.; Krykunov, M.; van Lenthe, E.; McCormack, D. A.; Michalak, A.; Mitoraj, M.; Morton, S. M.; Neugebauer, J.; Nicu, V. P.; Noodleman, L.; Osinga, V. P.; Patchkovskii, S.; Pavanello, M. P. C. A.; Philipsen, P. H. T.; Post, D.; Pye, C. C.; Ramanantoanina, H.; Ramos, P.; Ravenek, W.; Rodríguez, J. I.; Ros, P.; Rüger, R.; Schipper, P. R. T.; Schlüns, D. v. S. H.; Schreckenbach, G.; Seldenthuis, J. S.; Seth, M.; Snijders, J. G.; Solà, M. M. S.; Swart, M.; Swerhone, D.; te Velde, G.; Tognetti, V.; Vernooijs, P.; Versluis, L.; Visscher, L.; Visser, O.; Wang, F.; Wesolowski, T. A.; 
van Wezenbeek, E. M.; Wiesenekker, G. W. S. K.; Woo, T. K.; Yakovlev, A. L., "ADF2017, SCM, Theoretical Chemistry, Vrije Universiteit, Amsterdam, The Netherlands, https://www.scm.com", 2017.

[52] Lenthe, E. v.; Baerends, E. J.; Snijders, J. G., J. Chem. Phys., 1993, 99, 4597-4610.

[53] Noodleman, L., J. Chem. Phys., 1981, 74, 5737-5743.

[54] Ernzerhof, M.; Scuseria, G. E., J. Chem. Phys., 1999, 110, 5029-5036.

[55] Adamo, C.; Barone, V., J. Chem. Phys., 1999, 110, 6158-6170.

[56] Becke, A. D., J. Chem. Phys., 1993, 98, 5648-5652.

[57] Van Lenthe, E.; Baerends, E. J., J. Comput. Chem., 2003, 24, 1142-1156.

[58] Heisenberg, W., Phys. 1926, 38, 411-426.

[59] Dirac, P. A. M.; Fowler, R. H., Proc. Roy. Soc., 1929, 123, 714-733.

[60] Van Vlek, J. H., The Theory of electric and magnetic susceptibilities, Oxford University Press, Oxford: 1932.

Received: 02 September 2020

Accepted: 20 October 2020

Published online: 30 October 2020

ORCID ID for authors

Xiao-Lei Li: 0000-0002-1648-9459

Frédéric Gendron: 0000-0002-1896-3978

Boris Le Guennic: 0000-0003-3013-0546

Jinkui Tang: 0000-0002-8600-7718

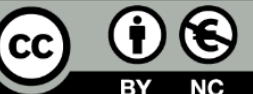

This article is licensed under a Creative Commons Attribution-NonCommercial 4.0 International License, which permits use, sharing, adaptation, distribution and reproduction in any medium or format, as long as it is non-commercial, you give appropriate credit to the original author(s) and the source, provide a link to the Creative Commons license, and indicate if changes were made. The images or other third-party material in this article are included in the article's Creative Commons license, unless indicated otherwise in a credit line to the material. If material is not included in the article' s Creative Commons license and your intended use is not permitted by statutory regulation or exceeds the permitted use, you will need to obtain permission directly from the copyright holder. To view a copy of this license, visit http://creativecommons.org/licenses/by/4.0/. 